\title{
Functional analysis of human RPS14 null alleles
}

\author{
José Martín-Nieto* and Donald J. Roufa† \\ Division of Biology and Center for Basic Cancer Research, Kansas State University, Manhattan, Kansas 66506, USA \\ *Present address: Instituto de Investigaciones Biomédicas, Consejo Superior de Investigaciones Científicas, Arturo Duperier 4, E-28029 Madrid, Spain \\ †Author for correspondence (e-mail: droufa@ksu.edu)
}

\section{SUMMARY}

Previously we described a large collection of cloned human DNAs that encode chemically defined missense mutations within the ribosomal protein $\mathrm{S} 14$ sequence. We determined that biologically inactive (i.e. null) alleles resulted primarily from point mutations targeted to two internal segments of the S14-coding sequence and designated these functionally critical regions as domains $B$ and $D$. Further, we inferred that structural determinants within domains $B$ and $D$ are required for proper incorporation of the $\mathrm{S} 14$ protein into nascent $40 \mathrm{~S}$ ribosomal particles and/or for the normal function of mature cytoplasmic ribosomes. In this study we have used immunofluorescence to monitor the intracellular trafficking of epitopically labeled human S14 protein isoforms transiently expressed by cultured Chinese hamster cells. Data obtained distinguish null alleles of RPS14 which encode proteins that are not incorporated into pre-ribosomal subunit particles from null alleles whose products are compatible with normal ribosome assembly processes but result in functionally inactive cytoplasmic $\mathbf{4 0}$ $\mathrm{S}$ ribosomal subunits. Mutations assigned to the first allele class involve amino acid replacements located within S14 domains B and D; whereas mutations assigned to the second class are distributed throughout the S14 proteincoding sequence.

Key words: Human RPS14 gene, Ribosomal protein, Mutant, Intracellular protein trafficking, Ribosomal subunit assembly

\section{INTRODUCTION}

Eukaryotic ribosome assembly is a complex process that depends on the regulated trafficking of multiple proteins into and out of the nucleolus (Hadjiolov, 1985; Warner, 1989; Melese and Xue, 1995). Approximately 80 ribosomal proteins (r-proteins) are synthesized in the cytoplasm and must be transported to the nucleolus for assembly with precursor ribosomal RNAs (pre-rRNAs) to form pre-ribosomal particles. Through a series of maturation steps involving sequential incorporation of r-proteins and site-specific pre-rRNA cleavages, nascent ribonucleoprotein particles are transformed into functional 40 $\mathrm{S}$ and $60 \mathrm{~S}$ ribosomal subunits. Mature ribosomal subunits then are exported from the nucleolus to the cytoplasm, where they are recruited to the cell's protein biosynthetic machinery (Khanna-Gupta and Ware, 1989; Bataillé et al., 1990; Ware and Khanna-Gupta, 1990). A wealth of genetic and molecular data support this scheme for ribosomal subunit maturation in a variety of eukaryotic organisms (Warner and Soeiro, 1967; Kumar and Warner, 1972; Warner, 1989; Moritz et al., 1990, 1991; Deshmukh et al., 1993; Ripmaster et al., 1993; Yeh and Lee, 1995).

In vertebrates the chromosomal locus encoding the $40 \mathrm{~S}$ ribosomal subunit protein $\mathrm{S} 14, \mathrm{RPS14}$, is unique in its suitability for detailed genetic and molecular genetic analyses. Mammalian S14 is composed of 151 amino acids (Boersma et al., 1979a) and is encoded by a gene that contains five exons which span $~ 5$ kbp of chromosomal DNA (Rhoads et al., 1986; Rhoads and Roufa, 1991). Chemically-induced mutations near the 3 '-end of RPS14 in Chinese hamster ovary CHO-K1 cells are responsible for recessive resistance to the translational inhibitor emetine; and $\mathrm{CHO}-\mathrm{K} 1$ cells expressing this phenotype can be isolated efficiently in tissue culture (Gupta and Siminovitch, 1977; Boersma et al., 1979a,b; Madjar et al., 1983; Tasheva and Roufa, 1993). Several wild-type and mutant RPS14 alleles have been obtained as cloned cDNAs (Rhoads and Roufa, 1985; Chen et al., 1986; Nakamichi et al., 1986) and chromosomal segments (Rhoads et al., 1986; Rhoads and Roufa, 1991) from Chinese hamster and human cells as well as from a variety of other eukaryotic species (Larkin et al., 1987; Brown et al., 1988; Larkin et al., 1989; Paz et al., 1989; Perelman and Boothroyd, 1990; Tyler and Harrison, 1990; Larson and Rossi, 1991; Aerne et al., 1994; Nelson et al., 1994; Wilson et al., 1994). Further, CHO cell lines carrying transgenic S14 DNA sequences have been constructed to characterize the biological activities of mutationally altered RPS14 genes (Diaz et al., 1990, 1991; Diaz and Roufa, 1992; Roufa, 1996).

In a previous report we described a large collection of cloned RPS14 DNAs that encode defined missense point mutations arrayed throughout the human S14 gene (Diaz and Roufa, 1992). The locations and properties of these mutations suggested that the $\mathrm{S} 14$ polypeptide is composed of five genetic domains, designated A-E, whose boundaries correspond closely with four of the RPS14 gene's five exons. S14 protein's amino terminal A domain (amino acid residues 1-20) was unnecessary for biological activity, as none of the mutations affecting this portion of the gene, including large deletion 
mutations, interfered with transgenic S14 function in $\mathrm{CHO}$ cells. In contrast, two other S14 polypeptide segments (domain B, amino acids 24-49; and domain D, amino acids 107-131) were crucial for the ribosomal protein's biological activity. Most mutations affecting these regions of the gene, including conservative amino acid replacements, abrogated the S14 protein's activity in CHO cells. Accordingly, we concluded that RPS14 domains B and D include determinants which apparently are necessary for the S14 protein's incorporation into 40 $\mathrm{S}$ pre-ribosomal particles and/or for the normal function of mature $40 \mathrm{~S}$ ribosomal subunits.

To verify this interpretation and further characterize our collection of human RPS14 mutations, we immunologically labeled nineteen biologically inactive, i.e. null, alleles and monitored the intracellular fates of these genes' proteins following transgenic expression in cultured CHO cells. In this report, RPS14 null alleles are defined as cloned S14 minigenes which, when transfected into emetine-resistant $\mathrm{CHO}$ cells, do not restore the emetine-sensitive phenotype associated with biologically active mammalian RPS14 genes (Boersma et al., 1979b; Madjar et al., 1982; Rhoads and Roufa, 1985, 1987a; Diaz and Roufa, 1992).

\section{MATERIALS AND METHODS}

\section{Materials}

Tissue culture medium (Dulbecco's modification of Eagle's minimal medium), fetal bovine serum, Lipofectamine, Nonidet P40, G418, Escherichia coli $\mathrm{TB} 1$ and the bacterial plasmid pUC13 were obtained from Life Technologies, Inc. The plasmid pET-3d and a murine monoclonal antibody directed against a 12 amino acid bacteriophage T7 protein 10 epitope (T7.Tag) were products of Novagen, Inc. Normal goat serum was obtained from Colorado Serum Co., and FITC-labeled goat anti-murine immunoglobulins (Igs) was purchased from Cappel Organon Teknika. Restriction endonucleases were from Promega Corp., Life Technologies, Inc. and New England Biolabs, Inc. E. coli DNA polymerase (Klenow fragment) was a product of United States
Biochemical Corp. Tween-20, saponin, phenylmethylsulfonyl fluoride, Evans Blue, aprotinin and leupeptin were obtained from Sigma Chemical Co. $\left[\alpha^{32} \mathrm{P}\right] \mathrm{dCTP}(800 \mathrm{Ci} / \mathrm{mmol})$ and $\left[\alpha^{32} \mathrm{P}\right] \mathrm{rUTP}$ $(3,000 \mathrm{Ci} / \mathrm{mmol})$ were from DuPont-New England Nuclear Corp. ${ }^{125} \mathrm{I}-$ labeled Protein A $(>30 \mathrm{Ci} / \mathrm{mg})$ was purchased from ICN Biomedicals Inc. Nitrocellulose filter membranes (Immobilon-NC) were from Millipore Corp. DNA oligonucleotides were synthesized by the Biotechnology Core Facility at Kansas State University.

Human RPS14 DNA and protein sequences (Rhoads et al., 1986; Diaz and Roufa, 1992) are deposited in GenBank under accession numbers M13641 and M13934. Recombinant plasmids carrying single-base missense mutations within the human S14 protein-coding sequence (pMS14-2 to pMS14-90) have been described (Diaz and Roufa, 1992).

\section{Transgenic expression of epitopically labeled human S14 alleles by cultured $\mathrm{CHO}$ cells}

All recombinant S14 DNAs were constructed in the plasmid vector pUC13 using $E$. coli TB1 as the bacterial host. Human S14 proteins were immunologically labeled by in-frame insertion of a 57 bp DNA sequence specifying the T7.Tag epitope. The T7 protein 10 DNA sequence used was excised from plasmid pET-3d (Studier et al., 1990) as a $35 \mathrm{bp} \mathrm{NcoI-BamHI}$ fragment which was ligated to the BamHI site of pUC13. After addition of a synthetic $10 \mathrm{bp} \mathrm{NcoI-TaqI}$ adapter, the DNA was introduced as a TaqI fragment into domain A of the human S14 expression plasmid pCS14-140 (Diaz and Roufa, 1992) between the codewords specifying Pro-3 and Arg-4. To increase expression of transgenic human S14, 547 bp of human RPS14 downstream chromosomal DNA, obtained from plasmid pCS14-83 (Overman et al., 1993), was appended to the construct as an SspI-HindIII DNA fragment. The resulting plasmid was designated pCS14Tag-WT (Fig. $1)$.

Mutant RPS14 alleles were labeled with the T7.Tag epitope by replacement of the Bsu36I-SfiI (284 bp) or Bsu36I-SspI (417 bp) DNA fragments in pCS14Tag-WT with analogous DNA fragments derived from cloned mutant genes pMS14-2 through pMS14-90 (Diaz and Roufa, 1992). pMS14-57 is an allele that carries an amino acid replacement (Ser-114 $\rightarrow$ Phe) as well as a single-base deletion $\left(\boldsymbol{}_{382}\right)$ (Diaz and Roufa, 1992). pMS14-57A, which harbors only the amino acid replacement, was constructed by exchanging the 307 bp Bsu36IAvaI DNA fragment in pCS14Tag-WT with the comparable fragment

\section{S14 Carboxyl Epitope}

Fig. 1. Diagram of human ribosomal protein S14 DNA sequence carried by plasmid pCS14Tag-WT. This DNA fragment encodes the 12 amino acid T7.Tag epitope inserted into the TaqI site in RPS14 exon II as well as the 15 amino acid S14 carboxyl peptide epitope (highlighted by boxes). Nucleotide and amino acid sequences of these epitopes are indicated, as are restriction endonuclease cleavage sites mentioned in the text. The cDNA sequence encoding RPS14 exons II-V is represented by a thick line, and the cloned segment of downstream genomic DNA (547 bp), by a thinner line.

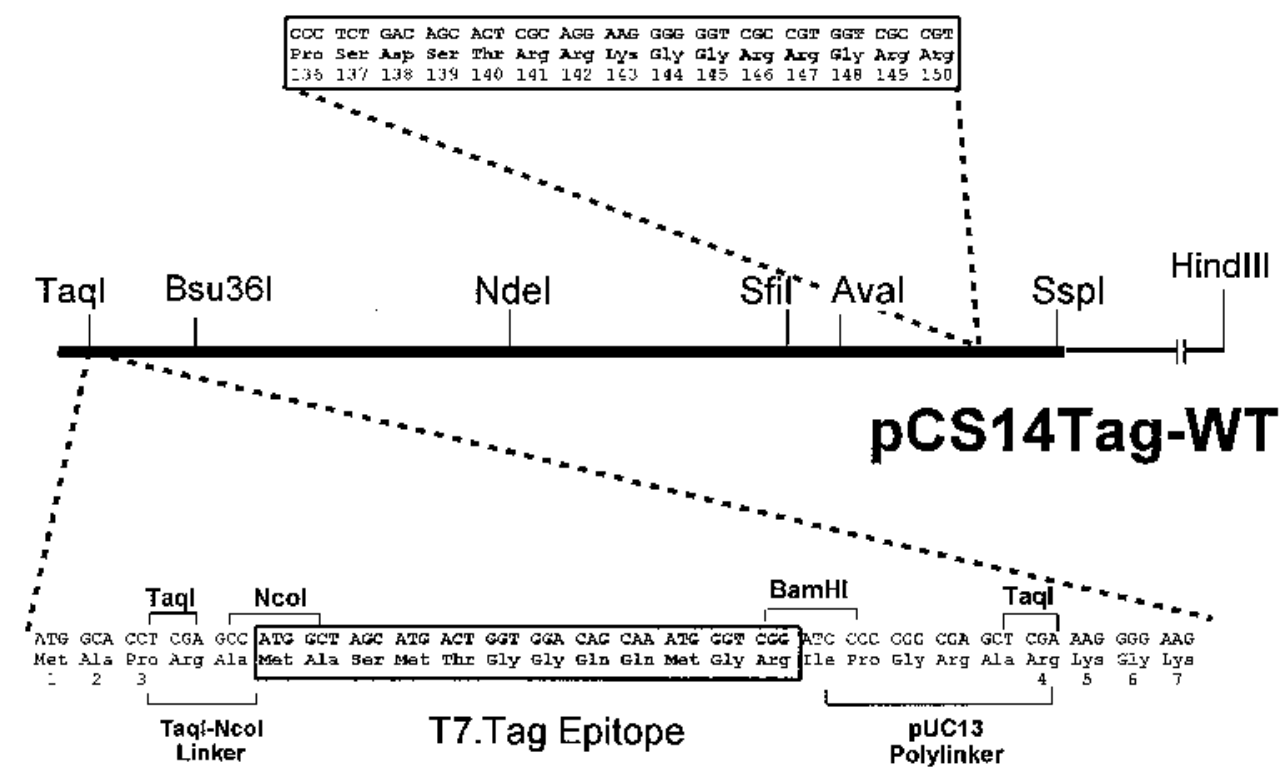


of pMS14-57. All recombinant DNA structures were verified by detailed restriction maps and DNA sequence analyses as described (Rhoads and Roufa, 1985; Rhoads et al., 1986; Brown et al., 1988; Diaz et al., 1991; Rhoads and Roufa, 1991; Diaz and Roufa, 1992; Tasheva and Roufa, 1993).

For transient expression of mutant RPS14 alleles, $100 \mathrm{~mm}$ tissue culture dishes were inoculated with $10^{6}$ emetine-resistant $\mathrm{Em}^{\mathrm{r}}-2-2$ CHO cells (Madjar et al., 1982, 1983; Rhoads and Roufa, 1985) and cultured for 12-16 hours. Recombinant plasmid DNAs (10 $\mathrm{kg})$ encoding human S14 alleles were introduced into the cells using the Lipofectamine-mediated transfection protocol described by that reagent's manufacturer (Life Technologies, Inc.). To obtain transformed cell clones that stably express human S14 DNAs, Em ${ }^{\mathrm{r}}-2-2$ cells were co-transfected with pSV2neo (Southern and Berg, 1982) and RPS14 DNAs using the polybrene-dimethylsulfoxide protocol described previously (Rhoads and Roufa, 1987a). Efficient transcription of recombinant $\mathrm{S} 14$ alleles in $\mathrm{CHO}$ cells, including biologically inactive null alleles, was confirmed by RNase $A+T_{1}$ protection assays using ${ }^{32} \mathrm{P}$-labeled human S14 antisense RNA probes (Brown et al., 1988; Diaz and Roufa, 1992; Overman et al., 1993). The biological activities of mutated S14 alleles also were assessed phenotypically in stably transformed CHO cells using the clonogenic assay described previously (Diaz and Roufa, 1992).

\section{Preparation of protein samples for immunological analysis}

Transiently or stably transformed Chinese hamster cells were scraped from culture monolayers and washed by centrifugation $(500 \mathrm{~g}, 5$ minutes) with phosphate buffered saline (PBS) containing $\mathrm{CaCl}_{2}(1$ $\mathrm{mM}), \mathrm{MgCl}_{2}(0.5 \mathrm{mM})$ and $0.1 \%(\mathrm{w} / \mathrm{v})$ glucose. Cells were resuspended in a buffer composed of $30 \mathrm{mM}$ Tris- $\mathrm{HCl}, \mathrm{pH} 7.5,100 \mathrm{mM}$ $\mathrm{NaCl}, 1 \mathrm{mM} \mathrm{MgCl} 2,0.5 \mathrm{mM} \mathrm{CaCl} 2$, phenylmethylsulfonyl fluoride $(10 \mathrm{~g} / \mathrm{ml})$, leupeptin $(2 \mathrm{~g} / \mathrm{ml})$ and aprotinin $(2 \mathrm{~g} / \mathrm{ml})$ and lysed by addition of $0.5 \%(\mathrm{v} / \mathrm{v}) \mathrm{NP} 40\left(0^{\circ} \mathrm{C}\right.$ for 10 minutes $)$. Lysates were resolved into cytoplasmic, nuclear and ribosomal subfractions by differential centrifugation (Boersma et al., 1979a; Madjar et al., 1983) and ribosomal proteins were extracted from each subcellular fraction and alkylated for electrophoretic analysis (Boersma et al., 1979a; Madjar et al., 1982, 1983).

\section{Immunological detection of human S14 proteins expressed by $\mathrm{CHO}$ cells}

Two antisera were used to assess the expression of human S14 alleles in transformed $\mathrm{CHO}$ cells. One was a polyclonal rabbit serum directed against the carboxyl terminus of mammalian r-protein S14. It was obtained by immunizing rabbits with a synthetic, 15 amino acid peptide (S14 Pro-136 through Arg-150, Fig. 1) conjugated to keyhole limpet hemocyanin (Krishnamachary et al., 1994). Because the amino acid sequences of human and Chinese hamster S14 are identical (Rhoads and Roufa, 1985; Rhoads et al., 1986), this antiserum detects both species' S14 protein equally well. The other antibody was a monoclonal IgG directed against the T7.Tag epitope (Novagen, Inc.). This antibody does not react with normal $\mathrm{CHO}$ and human proteins, but efficiently detects recombinant human S14 proteins carrying the T7.Tag epitope.

Transgenic human S14 proteins expressed by $\mathrm{CHO}$ cells were assayed quantitatively on immunoblots and qualitatively in single cells by indirect immunofluorescence. For immunoblots, $\mathrm{CHO}$ cell protein samples were resolved by SDS-polyacrylamide gel electrophoresis and electrophoretic transfer to nitrocellulose membranes. The resulting membranes were incubated at room temperature in a blocking solution of $1 \%(\mathrm{w} / \mathrm{v})$ hemoglobin in PBS (2 hours) followed by incubations with antibody directed against T7.Tag or S14 carboxyl peptide (8-12 hours) and then with ${ }^{125}$ I-labeled Protein A $\left(2.5 \times 10^{5}\right.$ $\mathrm{cpm} / \mathrm{ml})$. After each incubation, membranes were washed extensively in PBS plus $0.1 \%(\mathrm{v} / \mathrm{v})$ Tween-20. Nitrocellulose membranes were air dried before exposure to X-ray film. For indirect immunofluorescence microscopy, transfected $\mathrm{CHO}$ cells were fixed in $80 \%(\mathrm{v} / \mathrm{v})$ methanol for 5 minutes. After washing with PBS, cells were treated at room temperature with $0.5 \%(\mathrm{w} / \mathrm{v})$ saponin (5 minutes); normal goat serum plus Evans Blue counterstain (1 hour); an appropriate dilution of T7.Tag monoclonal antibody (3 hours); and FITC-conjugated goat anti-mouse Igs (1 hour). All antibody incubations were followed by extensive washes in PBS containing $0.1 \%$ (w/v) saponin. After the final wash, cells were mounted in glycerol/PBS $(1: 1)$ and observed under ultraviolet light using a Nikon Optiphot epifluorescence photomicroscope.

\section{RESULTS}

\section{The T7.Tag epitope does not interfere with incorporation of human $\mathbf{S 1 4}$ into functional $40 \mathrm{~S}$ ribosomal subunits}

Inasmuch as human and Chinese hamster S14 proteins are identical 151 amino acid polypeptides, we used an epitope tagging strategy to distinguish between transgenic human and endogenous hamster $\mathrm{S} 14$ proteins in cells and extracts prepared from transfected Em $^{\mathrm{r}}-2-2$ cultures. The T7.Tag epitope was chosen as the immunological label because it is small (12 amino acid residues) and a commercially available monoclonal antibody directed against it does not crossreact with mammalian cell proteins. A DNA fragment encoding T7.Tag plus seven additional amino acid residues was inserted in frame into a cloned copy of human RPS14 near the $5^{\prime}$-end of exon II, within the nonessential A domain of the S14-coding sequence (Diaz and Roufa, 1992). The recombinant r-protein encoded by

A

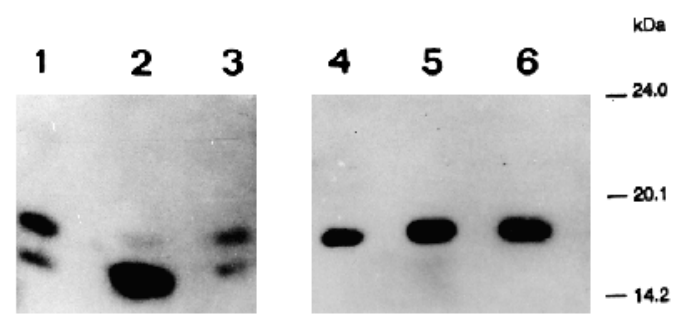

B

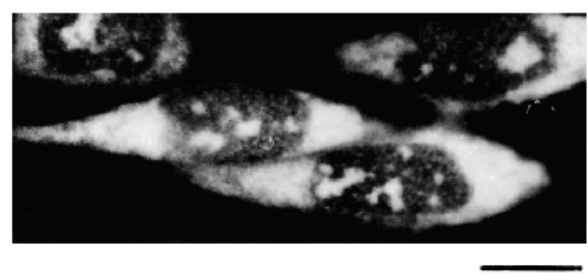

Fig. 2. Subcellular distribution of human r-protein S14 in stablytransformed CHO cells. (A) Immunoblot of subcellular protein fractions. Cytoplasmic proteins (100 $\mathrm{gg}$, lanes 1 and 4), nuclear proteins (100 $\mathrm{g}$, lanes 2 and 5) and purified ribosomal proteins (10 $\mathrm{gg}$, lanes 3 and 6) were resolved by electrophoresis through a $12.5 \%$ (w/v) polyacrylamide gel and electroblotted to a nitrocellulose membrane. Lanes 1-3 were analyzed with polyclonal rabbit anti-S14 carboxyl peptide serum diluted 1/1,000; and lanes 4-6 were analyzed with monoclonal anti-T7.Tag diluted $1 / 5,000$. Bound antibody was detected with ${ }^{125}$ I-labeled Protein A. Molecular sizes of protein standards analyzed on the same polyacrylamide gel are indicated at the right of the figure. (B) Indirect immunofluorescence staining pattern obtained using murine anti-T7.Tag monoclonal antibody and FITC-labeled goat anti-mouse Igs. Bar, $15 \mu \mathrm{m}$. 
this construct (pCS14Tag-WT, Fig. 1) is 19 amino acid residues $(\sim 2 \mathrm{kDa})$ larger than wild-type S14 and, as shown below, can be detected in cells as well as cell-free extracts using standard immunological and electrophoretic methods.

To determine whether the T7.Tag insert adversely affected r-protein S14 function in cultured CHO cells, pCS14Tag-WT was stably introduced into emetine-resistant $\mathrm{Em}^{\mathrm{r}}-2-2$ cells together with an excess of the selectable plasmid pSV2-neo (Southern and Berg, 1982). Most of the G418-resistant colonies isolated from transfected cultures (>85\%) were sensitive to emetine, indicating that the epitopically-labeled S14 protein functioned well enough to phenotypically mask the $\mathrm{Em}^{\mathrm{r}}$-2-2 drug resistance phenotype. In addition, cloned cell lines carrying stably integrated pCS14Tag-WT transgenes expressed both normal S14 $\left(M_{\mathrm{r}} \simeq 16,000\right)$ and the T7.Tag fusion $\mathrm{S} 14$ protein $\left(M_{\mathrm{r}} \simeq 18,000\right)$. As illustrated in Fig. 2A, antiserum directed against the $\mathrm{S} 14$ carboxyl epitope revealed the two S14 proteins on immunoblots of cytoplasmic (lane 1) and nuclear (lane 2) protein extracts. That both S14 antigens also were detected among proteins extracted from purified cytoplasmic ribosomal subunits (lane 3) indicated that T7.Tag does not interfere with the protein's incorporation into preribosomal particles nor does it preclude export of mature $40 \mathrm{~S}$ ribosomal subunits to the cell's cytoplasm. Indeed, the relative intensities of the two S14 protein bands observed in cytoplasmic extracts (lane 1) and purified ribosomal subunits (lane 3) suggested that the transgenic fusion protein was expressed and processed approximately as efficiently as the cells' endogenous S14. When the same three protein samples were analyzed with anti-T7.Tag antibody, only the epitopically-tagged protein $\left(M_{\mathrm{r}}\right.$ $\simeq 18,000$ ) was detected (Fig. 2A, lanes 4-6). Because neither normal nor epitopically tagged S14 proteins were detected in post-ribosomal cytosolic supernatant fractions (data not shown), we concluded that most, if not all, of the cytoplasmic S14 antigens visualized on immunoblots were contained within ribosomal subunit particles. In the experiment illustrated, the protein samples analyzed were optimized to yield comparable autoradiographic signals. When calculated on a 'per cell' basis, these data indicated that the great majority of cells' S14 antigen $(>90 \%)$ was located within cytoplasmic subcellular fractions. Only minor fractions of the antigen (generally $<10 \%$ ), presumably reflecting newly synthesized S14 protein, were detected among the proteins extracted from $\mathrm{CHO}$ cell nuclei.

Indirect immunofluorescence more precisely located the wild-type fusion $\mathrm{S} 14$ protein within $\mathrm{Em}^{\mathrm{r}}$-2-2 cells' nucleoli and cytoplasm (Fig. 2B). The immunofluorescence staining pattern obtained with anti-T7.Tag (Fig. 2B) was very similar to that observed when polyclonal anti-S14 carboxyl peptide antiserum was used to analyze transfected as well as non-transfected control cells (data not shown). Taken together, the immunologic and clonogenic data described above demonstrate that: (1) epitopically labeled pCS14Tag-WT transgene is accurately expressed by $\mathrm{CHO}$ cells; and (2) CHO cells efficiently process the wild-type $\mathrm{S} 14$ fusion protein and incorporate the protein into functional ribosomal subunits.

\section{Intracellular trafficking of mutated S14 proteins}

Nineteen null alleles of human RPS14, each carrying a single defined amino acid replacement (Diaz and Roufa, 1992), were labeled with T7.Tag to assess their intracellular processing. Cells were fixed 24 or 48 hours after transfection for analysis by indirect immunofluorescence. Four distinct immunofluorescence patterns were observed (Fig. 3). Cells transiently expressing the wild-type RPS14 transgene (pCS14Tag-WT) and several of its mutant alleles (see Table 1, Groups A and B) displayed intense cytoplasmic and nucleolar fluorescence (Fig. 3A). This immunostaining pattern was identical to the immunofluorescence observed in $\mathrm{CHO}$ cells stably expressing pCS14Tag-WT (Fig. 2B) and was designated the type I staining pattern. In contrast, the other S14 null alleles (see Table 1, Group C) were associated with intense nucleolar and/or nucleoplasmic fluorescence only. Cells displaying the type II immunofluorescence pattern cells showed nucleolar staining exclusively (Fig. 3B). Cells classified as exhibiting type III
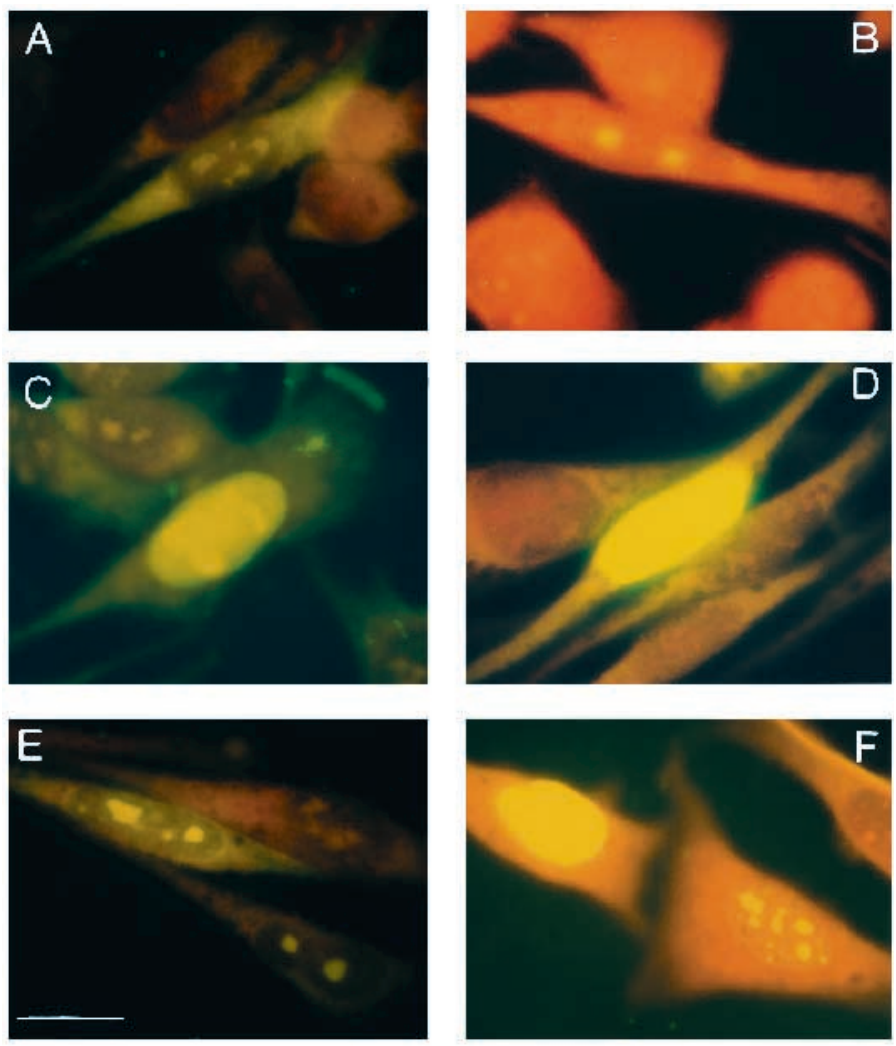

Fig. 3. Subcellular distribution of wild-type and mutant S14 polypeptides transiently expressed by $\mathrm{CHO}$ cells. Twenty-four $(\mathrm{B}, \mathrm{D}, \mathrm{E})$ or forty-eight $(\mathrm{A}, \mathrm{C}, \mathrm{F})$ hours after transfection with the epitopically labeled RPS14 alleles indicated, $\mathrm{Em}^{\mathrm{r}}-2-2$ cells were prepared for indirect immunofluorescence microscopy using murine anti-T7.Tag monoclonal antibody and FITC-labeled anti-mouse Igs. T7.tagged S14 polypeptides appear as yellow/green fluorescence. Cell regions devoid of the epitope as well as non-expressing cells are visualized with Evans Blue counterstain. The immunofluorescence patterns shown are as follows: (A) type I immunofluorescence, pCS14Tag-WT DNA. (B) Type II immunofluorescence, pCS14TagM13 DNA. The M13 null allele carries two point mutations: Phe$37 \rightarrow$ Leu and Asp-39 $\rightarrow$ Gly (Diaz and Roufa, 1992). (C) Type III immunofluorescence, pCS14Tag-M80 DNA (Met-124 $\rightarrow$ Lys; Diaz and Roufa, 1992). (D) Type IV immunofluorescence, pCS14Tag-M9 DNA (Cys-31 $\rightarrow$ Trp; Diaz and Roufa, 1992). (E) Types I and II immunofluorescence, pCS14Tag-M58 DNA. M58 specifies two amino acid replacements: Arg-117 $\rightarrow$ Lys and Asp-138 $\rightarrow$ Asn (Diaz and Roufa, 1992). (F) Immunofluorescence pattern types II and IV, pCS14Tag-M80 DNA. Bar, 20 m. 
immunofluorescence displayed intense nucleolar staining accompanied by substantial, but variable, staining in the surrounding nucleoplasm (Fig. 3C). Nucleoplasmic fluorescence was so intense in some type III cells that it obscured stained nucleoli (Fig. 3D) and therefore was designated as a separate immunofluorescence phenotype (the type IV pattern).

Although CHO cells transiently expressing wild-type S14 fusion protein showed type I immunofluorescence predominantly, cells transfected with most of the mutant S14 fusion genes displayed multiple alternative immunofluorescence patterns within single microscopic fields. For example, transient expression of the biologically-active mutant allele pCS14Tag-M58 produced cells with types I and II immunofluorescence (Fig. 3E); whereas expression of the null allele pCS14Tag-M80 resulted in cells that displayed types II, III and IV patterns (Fig. 3C and F). Based on these observations, it was clear that the four immunofluorescence patterns distinguished do not all represent steady-state phenotypes. Rather, some of the patterns appeared to reflect transition phenotypes within two distinct temporal sequences.

To investigate temporal relationships among immunoflu-
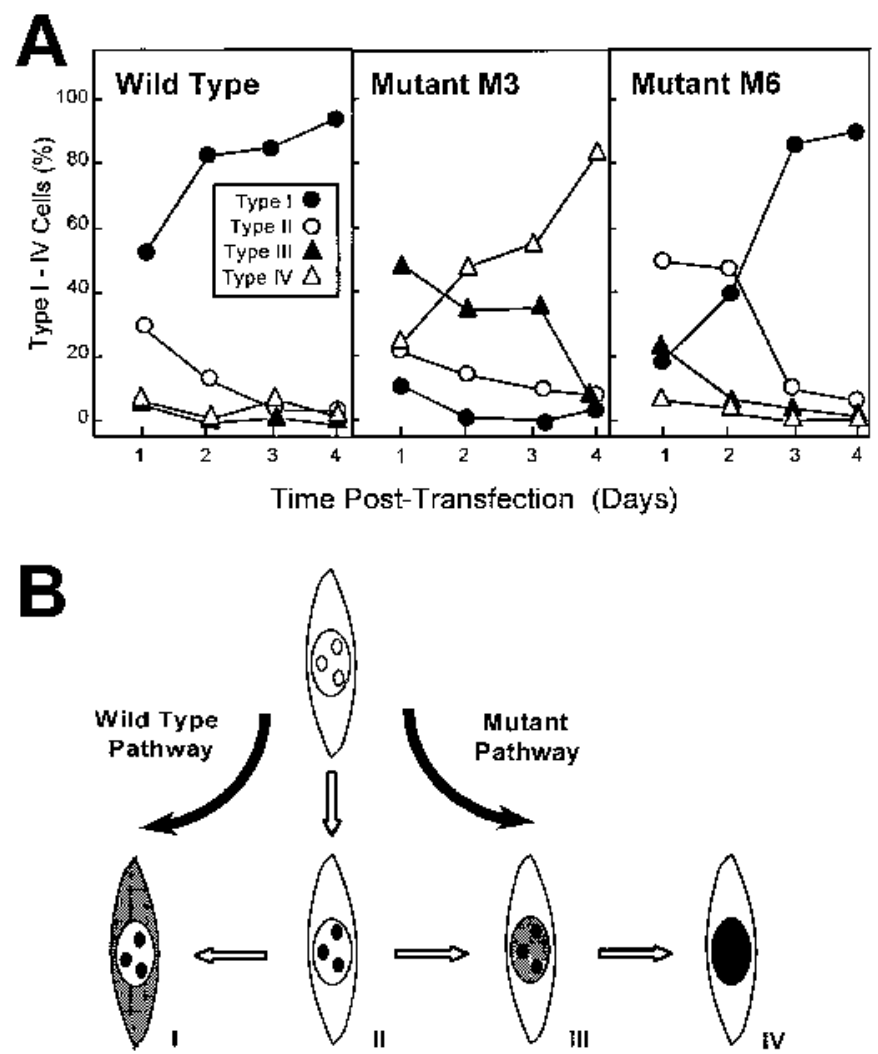

Fig. 4. (A) Immunofluorescence patterns observed during transient expression of T7.Tagged wild-type and mutant RPS14 alleles. CHO $\mathrm{Em}^{\mathrm{r}}-2-2$ cells were fixed one to four days post-transfection with wild-type pCS14Tag-WT or mutant pCS14Tag-M3 and pCS14TagM6 transgenes and processed for indirect immunofluorescence microscopy with monoclonal anti-T7.Tag antibody. At least 100 fluorescent cells were scored for each time point; and cells were classified as exhibiting types I-IV immunostaining patterns according to criteria described in the text. (B) Diagram of the temporal transitions among the immunofluorescence staining patterns inferred from data illustrated in A. orescence patterns I-IV, the fractions of cells displaying each pattern were evaluated at sequential times following transfection with several epitopically-labeled RPS14 alleles (Fig. 4). As illustrated in Fig. 4A, staining patterns types I and IV were the two end-state phenotypes observed. Staining patterns II and III appeared only transiently as cells progressed toward the types I or IV end-states. As illustrated in Fig. 4B, wild-type S14 protein transits the cells' nucleoli (type II immunofluorescence) and accumulates in the cytoplasm as a component of functional ribosomal particles (type I immunofluorescence). Few cells that express the wild-type protein displayed nucleoplasmic fluorescence (types III and IV fluorescence), suggesting that normal nucleoplasmic pools of free S14 protein and newly assembled ribosomal subunits are too small to be detected by indirect immunofluorescence. Cells expressing some mutated, biologically inactive S14 proteins (e.g. the M6 null S14 protein) also produced a type I steady state staining pattern, but achieved this fluorescence pattern more slowly than cells transfected with the wild-type fusion gene (Fig. 4A). Accordingly, the M6 fusion protein appeared to be transported into the cells' nucleoli with normal kinetics, but thereafter was incorporated into $40 \mathrm{~S}$ ribosomal particles and exported to the cytoplasm more slowly than wild-type S14. Thus, the M6 point mutation (Thr-45 $\rightarrow$ Ile; Diaz and Roufa, 1992) appears to retard, but not preclude, assembly of S14 into pre-ribosomal particles destined for export to the cytoplasm.

In contrast, cells expressing other null mutant S14 proteins displayed the type IV immunofluorescence end-state pattern. As illustrated in Fig. 4A, transgenic M3 fusion protein (Cys$31 \rightarrow$ Ser; Diaz and Roufa, 1992) was transported into CHO cell nucleoli with normal or near-normal kinetics to produce a transient type II staining pattern (open circles). However, $\mathrm{CHO}$ cells did not re-export the M3 protein to the cytoplasm. Rather, the M3 protein accumulated in the cells' nucleoplasm (staining patterns types III and IV, shaded and unshaded triangles). Unusually intense nucleoplasmic fluorescence in these cells probably indicates free M3 S14 protein trapped in the nucleoplasm during its import to the nucleolus. Alternatively, it might reflect excess unassembled ribosomal protein that has 'leaked' from nucleoli with saturated internal pools of S14 protein. In either case, intracellular trafficking patterns which result in types III and IV immunofluorescence patterns (indicated diagrammatically as the 'Mutant Pathway' in Fig. 4B) have been interpreted to indicate mutations which preclude the S14 protein's incorporation into nucleolar pre-ribosomal subunit particles.

Kinetic studies, such as those illustrated in Fig. 4A, were carried out on nineteen of the mutant S14 DNA clones previously classified as null alleles (Diaz and Roufa, 1992). Each of the mutant DNAs was assigned to one of three phenotypic classes based on the immunofluorescence staining patterns produced (Table 1). Eleven of the null alleles encode proteins that resulted in the type I immunofluorescence end-state pattern illustrated in Fig. 3A. Accordingly, these mutated S14 proteins appeared to be incorporated into functionally inactive $40 \mathrm{~S}$ ribosomal particles which ultimately produced intense cytoplasmic fluorescence. Five of these mutants achieved the type I end-state with kinetics comparable to the wild-type S14 fusion protein (these are classified as Group A mutations in Table 1); and six mutants approached the type I end-state pattern slower than cells expressing pCS14Tag-WT (Group B 
Table 1. Intracellular trafficking of mutant human S14 proteins transiently expressed in cultured Chinese hamster ovary (CHO) cells*

\begin{tabular}{cc}
\hline Clone & Amino acid substitution(s) \\
A. Mutant S14 proteins that are incorporated into 40 S subunits and transported
\end{tabular}
to the cytoplasm normally:

$\begin{array}{ll}\text { M4 } & \text { Ser-70 } \rightarrow \text { Leu } \\ \text { M5 } & \text { Lys-50 } \rightarrow \text { Glu } \\ \text { M53 } & \text { Arg- } 98 \rightarrow \text { Leu } \\ \text { M54 } & \text { Ala-74 } \rightarrow \text { Val } \\ \text { M55 } & \text { Arg- } 117 \rightarrow \text { Lys }\end{array}$

B. Mutant S14 proteins whose incorporation into $40 \mathrm{~S}$ subunits and transport to the cytoplasm is slower than normal:

$\begin{array}{ll}\text { M6 } & \text { Thr-45 } \rightarrow \text { Ile } \\ \text { M23 } & \text { Gly-49 } \rightarrow \text { Asp } \\ \text { M57A } & \text { Ser-114 } \rightarrow \text { Phe } \\ \text { M60 } & \text { Gly-123 } \rightarrow \text { Ser } \\ \text { M63 } & \text { Asp-131 } \rightarrow \text { Asn } \\ \text { M90 } & \text { Thr-133 } \rightarrow \text { Ile }\end{array}$

C. Mutant S14 proteins that are neither incorporated into $40 \mathrm{~S}$ subunits nor transported to the cytoplasm:

\begin{tabular}{|c|c|}
\hline M3 & Cys-31 $\rightarrow$ Ser \\
\hline M7 & Cys-31 $\rightarrow$ Tyr \\
\hline M9 & Cys-31 $\rightarrow \operatorname{Trp}$ \\
\hline M17 & His- $43 \rightarrow \mathrm{Tyr}$ \\
\hline M44 & Gly-111 $\rightarrow$ Arg \\
\hline M67 & Gly-127 $\rightarrow$ Arg \\
\hline M80 & Met- $124 \rightarrow$ Lys \\
\hline M88 & Ile-126 $\rightarrow$ Asn \\
\hline
\end{tabular}

* CHO cells (clone $\mathrm{Em}^{\mathrm{r}}$-2-2) expressing the cloned T7.Tagged mutant RPS14 alleles listed were analyzed by indirect immunofluorescence at several times following transfection. Transgenes whose products produced type I immunofluorescence with kinetics similar to the wild-type S14 polypeptide are listed in group A. Alleles whose peptide products displayed type I immunofluorescence significantly slower than wild type (such as the mutant M6 polypeptide shown in Fig. 4A) are listed in group B. Transgenes whose protein products accumulated within the cells' nucleoli and nucleoplasm (types III and IV immunofluorescence) are listed in group C.

mutations, Table 1). The latter group of mutated fusion proteins apparently are incorporated into $40 \mathrm{~S}$ pre-ribosomal particles more slowly than wild-type S14 fusion protein. The remaining eight mutated fusion proteins accumulated within the $\mathrm{CHO}$ cells' nucleoli and nucleoplasm (as evidenced by types III and IV immunofluorescence end-state patterns) and therefore were classified as proteins which are not incorporated into preribosomal subunits (Group C mutations, Table 1).

A diagram summarizing the locations and properties of the S14 null mutations analyzed by indirect immunofluorescence is illustrated in Fig. 5. In the figure, mutations which yielded the type I end-state immunofluorescence pattern are positioned above the horizontal line, whereas mutations that produced types III and IV end-state patterns are located below the line. The type I S14 alleles include mutant genes whose products were incorporated into $40 \mathrm{~S}$ ribosomal particles as efficiently as wild-type S14 protein (Group A alleles) as well as genes whose products were assembled into ribosomal particles more slowly (Group B alleles). Consistent with this interpretation, the type I mutations are distributed across most of the S14 protein-coding sequence and involve an approximately equal mixture of conservative (circles) and non-conservative (squares) amino acid replacements. In contrast, the eight trans-

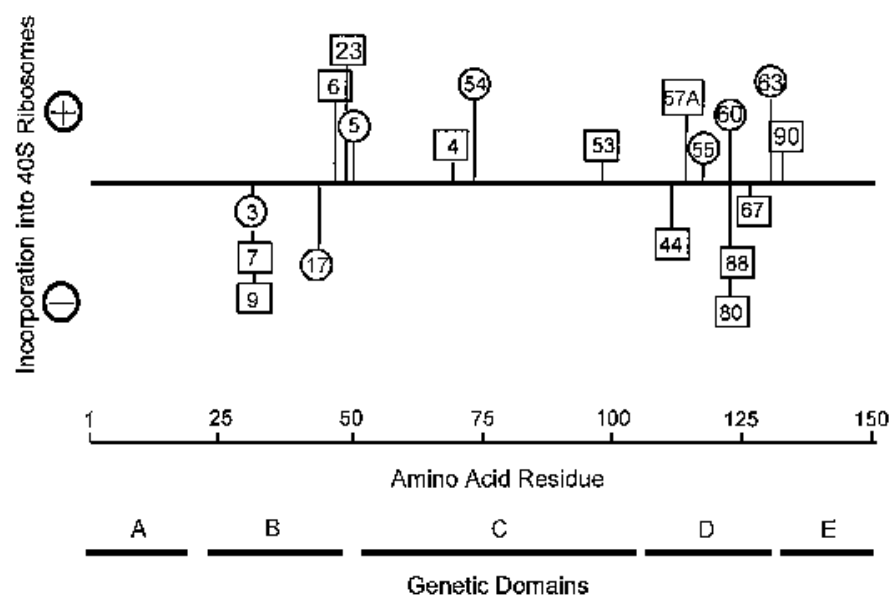

Fig. 5. Effects of null mutations on incorporation of r-protein S14 into $40 \mathrm{~S}$ ribosomal subunits. The horizontal axis represents the 151 amino acid human S14 sequence. Residue numbers are indicated on the scale below. Mutations compatible with the S14 protein's incorporation into pre-ribosomal subunits are displayed above the axis; and mutations which preclude the protein's incorporation into ribosomal particles are positioned below the axis. Individual amino acid replacements are identified by the clone numbers listed in Table 1. Conservative amino acid substitutions, as judged by the PAM-250 matrix (Dayhoff, 1978), are represented as circles; and radical amino acid replacements are represented by squares. The S14 polypeptide's genetically-defined functional domains A-E (Diaz and Roufa, 1992) are indicated at the bottom of the figure.

genes associated with types III and IV staining patterns (Group C alleles) carry mutations clustered within RPS14 domains B and $\mathrm{D}$. These domains previously were identified as critical for ribosome assembly and function by genetic criteria alone (Diaz and Roufa, 1992). As might be expected for mutations that preclude r-protein incorporation into ribosomal particles, most of the Group $\mathrm{C}$ mutations involve non-conservative amino acid substitutions. Interestingly, the six Group B mutations which delay S14 protein's incorporation into nascent $40 \mathrm{~S}$ preribosomal particles (M6, M23, M57A, M60, M63 and M90) also map to domains B and D. Accordingly, our data indicate that structural determinants within RPS14 domains $\mathrm{B}$ and D are required for the nucleolar functions that mediate S14 incorporation into pre-ribosomal particles.

\section{DISCUSSION}

For lack of robust cell-free methods by which to assess intracellular trafficking of mammalian r-proteins and their assembly into pre-ribosomal subunits, we employed an epitope labeling strategy and transient expression assay to characterize our collection of human RPS14 null alleles. This assay was based on the observation that in higher eukaryotic cells newly-synthesized r-proteins are rapidly transported to the nucleolus, where they are incorporated into pre-ribosomal subunit particles. When fully assembled and modified, mature ribosomal subunits are exported to the cytoplasm to function as part of the cell's protein biosynthetic apparatus. Based on this scheme, RPS14 mutations which preclude export of the encoded ribosomal protein from the nucleolus to the cytoplasm are 
interpreted as abrogating S14's incorporation into preribosomal subunit particles within the nucleolus. To be more precise, RPS14 mutations which interfere with ribosomal subunit assembly or maturation as well as mutations which preclude export of mature $40 \mathrm{~S}$ ribosomal subunits to the cytoplasm also might fall into this phenotypic class. Nonetheless, the assay described in this report permitted us to resolve our collection of S14 null alleles into two phenotypic classes: (i) alleles that encode ribosomal proteins which are incorporated into nonfunctional $40 \mathrm{~S}$ ribosomal subunits exported to the cytoplasm; and (ii) alleles whose products accumulate either as free ribosomal proteins or as structural components of immature $40 \mathrm{~S}$ pre-ribosomal subunits within the nucleolus and nucleoplasm.

Detailed biochemical characterization is necessary to verify the molecular status of S14 proteins encoded by the two classes of null mutations described above. Unfortunately, the transient expression assay employed in these studies is not suitable for critical biochemical analysis because only small fractions of cells within the $\mathrm{CHO}$ cell cultures $(<10 \%)$ express the S14 transgenes. For this reason, detailed molecular analysis requires homogenous, cloned populations of $\mathrm{CHO}$ cells which continuously express the mutant transgenes. Toward this end, we have attempted to isolate $\mathrm{CHO}$ cell lines stably transformed with each of the S14 null alleles described in this report using the polybrene-mediated protocol described in Materials and Methods. Although this approach readily yielded cloned $\mathrm{CHO}$ cell lines that constitutively express high levels of wild-type (as illustrated by data in Fig. 2) and biologically functional mutant S14 transgenes (Diaz and Roufa, 1992), repeated attempts to isolate cells which stably express S14 null alleles all have failed. In every case, G418-resistant colonies were obtained with lesser frequency $(35-50 \%)$ than simultaneous control transfections of the wild-type S14 transgene. More importantly, none of the transformed cell lines isolated expressed the transgenic T7.tagged S14 proteins or their messenger RNAs (J. Martín-Nieto and D. J. Roufa, unpublished). In light of these results, we concluded that continuous expression of S14 null alleles under control of the human RPS14 transcriptional promoter (Overman et al., 1993) is lethal for $\mathrm{CHO}$ cells growing in tissue culture and that isolation of viable cell lines which express the RPS14 null alleles must await development of a transgene expression system driven by a tightly regulated, conditional promoter.

Three features of our experimental protocol ensured that the epitope label used in these studies did not adversely affect the biological activities of S14 fusion proteins. First, the T7.Tag epitope was chosen because it is small (19 amino acid residues) and increases the size of S14 fusion polypeptides by only $\sim 12 \%$. Second, the T7.Tag epitope was inserted into S14 domain A, a functionally dispensable segment of the ribosomal protein (Diaz and Roufa, 1992). And third, the biological activity of epitopically labeled wild-type fusion protein was demonstrated by the fact that it rescued the recessive, emetine resistance phenotype encoded by the RPS14 allele carried by CHO Emr-2-2 cells (Madjar et al., 1982, 1983; Nakamichi et al., 1983; Rhoads and Roufa, 1985, 1987a). Data illustrated in Fig. 2A indicate that transgenic wild-type $\mathrm{S} 14$ fusion protein $\left(M_{\mathrm{r}} \simeq 18,000\right)$ was incorporated into functional Chinese hamster $40 \mathrm{~S}$ ribosomes about as efficiently as the r-protein $\left(M_{\mathrm{r}}\right.$

Table 2. Evolutionary conservation of amino acids involved in human RPS14 null mutations

\begin{tabular}{|c|c|c|c|c|c|c|c|c|c|c|c|c|c|c|c|c|c|c|}
\hline \multirow[b]{2}{*}{ r-Protein S14 homologs* } & \multirow{2}{*}{$\begin{array}{l}\text { GenBank } \\
\text { access. no. }\end{array}$} & \multicolumn{16}{|c|}{ r-Protein $\mathrm{S} 14$ amino acid residues } & \multirow[b]{2}{*}{133} \\
\hline & & 31 & 43 & 45 & 49 & 50 & 70 & 74 & 98 & 111 & 114 & 117 & 123 & 124 & 126 & 127 & 131 & \\
\hline \multicolumn{19}{|l|}{ Vertebrates: } \\
\hline Homo sapiens & M13934 & $\mathrm{C}$ & $\mathrm{H}$ & $\mathrm{T}$ & G & $\mathrm{K}$ & $\mathrm{S}$ & A & $\mathrm{R}$ & G & $\mathrm{S}$ & $\mathrm{R}$ & G & M & I & $\mathrm{G}$ & $\mathrm{D}$ & $\mathrm{T}$ \\
\hline Cricetulus griseus & M35008 & $\bullet$ & $\bullet$ & $\bullet$ & $\bullet$ & $\bullet$ & $\bullet$ & $\bullet$ & $\bullet$ & $\bullet$ & $\bullet$ & $\bullet$ & $\bullet$ & $\bullet$ & $\bullet$ & $\bullet$ & $\bullet$ & $\bullet$ \\
\hline Rattus norvegicus & X15040 & $\bullet$ & $\bullet$ & $\bullet$ & $\bullet$ & $\bullet$ & $\bullet$ & $\bullet$ & $\bullet$ & $\bullet$ & $\bullet$ & $\bullet$ & $\bullet$ & $\bullet$ & $\bullet$ & $\bullet$ & $\bullet$ & $\bullet$ \\
\hline \multicolumn{19}{|l|}{ Arthropods: } \\
\hline Procambarus clarkii & D14609 & $\bullet$ & $\bullet$ & $\bullet$ & $\bullet$ & $\mathrm{R}$ & $\bullet$ & $\bullet$ & $\bullet$ & $\bullet$ & $\bullet$ & $\bullet$ & - & $\bullet$ & $\bullet$ & - & $\bullet$ & $\bullet$ \\
\hline Drosophila melanogaster & M21045 & A & $\bullet$ & $\bullet$ & $\bullet$ & $\mathrm{R}$ & $\bullet$ & $\bullet$ & $\bullet$ & $\bullet$ & $\bullet$ & $\bullet$ & $\bullet$ & $\bullet$ & $\bullet$ & $\bullet$ & $\bullet$ & $\bullet$ \\
\hline \multicolumn{19}{|l|}{ Nematode: } \\
\hline Caenorhabditis elegans & U00033 & A & $\bullet$ & $\bullet$ & $\bullet$ & $\mathrm{R}$ & $\bullet$ & $\bullet$ & $\bullet$ & $\bullet$ & $\bullet$ & $\bullet$ & - & $\bullet$ & $\bullet$ & $\bullet$ & - & - \\
\hline \multicolumn{19}{|l|}{ Hydrozoan: } \\
\hline Podocoryne carnea & X71384 & A & $\bullet$ & $\bullet$ & $\bullet$ & $\bullet$ & $\bullet$ & $\bullet$ & $\bullet$ & $\bullet$ & $\bullet$ & $\bullet$ & - & $\bullet$ & $\bullet$ & $\bullet$ & $\bullet$ & $\bullet$ \\
\hline \multicolumn{19}{|l|}{ Fungi: } \\
\hline Neurospora crassa & X53734 & A & $\bullet$ & $\bullet$ & $\bullet$ & $\mathrm{R}$ & $\bullet$ & $\bullet$ & $\bullet$ & $\bullet$ & $\bullet$ & $\bullet$ & $\bullet$ & $\bullet$ & $\bullet$ & $\bullet$ & $\bullet$ & $\bullet$ \\
\hline Saccharomyces cerevisiae & M16126 & A & $\bullet$ & $\bullet$ & $\bullet$ & $\bullet$ & $\bullet$ & $\bullet$ & $\bullet$ & $\bullet$ & A & $\bullet$ & $\bullet$ & $\mathrm{L}$ & $\bullet$ & - & - & $\bullet$ \\
\hline Kluveromyces lactis & X59860 & A & - & $\bullet$ & $\bullet$ & $\mathrm{R}$ & $\bullet$ & $\bullet$ & - & $\bullet$ & A & - & - & $\mathrm{L}$ & - & - & - & - \\
\hline \multicolumn{19}{|l|}{ Protozoan: } \\
\hline Trypanosoma brucei & M36124 & V & $\bullet$ & $\bullet$ & $\bullet$ & $\mathrm{R}$ & $\bullet$ & $\bullet$ & $\bullet$ & $\bullet$ & A & $\bullet$ & $\bullet$ & $\bullet$ & $\bullet$ & $\bullet$ & $\bullet$ & $\bullet$ \\
\hline \multicolumn{19}{|l|}{ Algae: } \\
\hline Chlamydomonas reinhardtii & U06937 & A & $\bullet$ & $\bullet$ & $\bullet$ & $\mathrm{R}$ & - & $\bullet$ & $\bullet$ & $\bullet$ & $\bullet$ & $\bullet$ & $\bullet$ & $\bullet$ & - & - & - & $\bullet$ \\
\hline \multicolumn{19}{|l|}{ Plants: } \\
\hline Arabidopsis thaliana & $\mathrm{Z} 17690$ & $?$ & $?$ & $?$ & $?$ & $?$ & $\bullet$ & $\bullet$ & $\bullet$ & $\bullet$ & $\bullet$ & $\bullet$ & $\bullet$ & $\bullet$ & $\bullet$ & $\bullet$ & $\bullet$ & $\bullet$ \\
\hline Zea mays & $\mathrm{P} 19950 \dagger$ & A & $\bullet$ & $\bullet$ & $\bullet$ & $\mathrm{R}$ & $\bullet$ & $\bullet$ & - & $\bullet$ & $\bullet$ & $\bullet$ & $\bullet$ & $\bullet$ & $\bullet$ & $\bullet$ & - & - \\
\hline
\end{tabular}

*r-Protein S14 amino acid sequences deposited in the GenBank database. The amino acid sequences were aligned using the PileUp software tool (Genetics

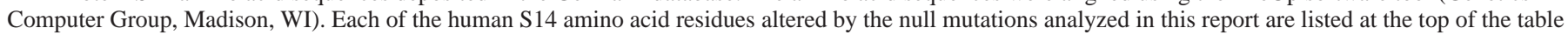

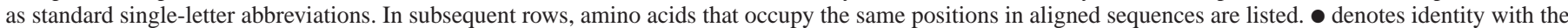
residue in human $\mathrm{S} 14$. ? indicates that the amino acid in this position is not known.

$\dagger$ This is a Swiss-Prot database accession number. 
$\simeq 16,000$ ) encoded by the cells' endogenous emetine resistance RPS14 allele.

Transitions among intracellular immunofluorescence staining patterns displayed by $\mathrm{CHO}$ cells which expressed epitopically-labeled S14 minigenes (Fig. 4A) were surprisingly slow. Others have used radioisotopic pulse labeling procedures to demonstrate that nascent ribosomal proteins are transported to the nucleolus and assembled into pre-ribosomal particles within minutes of their synthesis in cultured mammalian cells (Warner and Soeiro, 1967; Kumar and Warner, 1972). Therefore, the kinetics we observed over a four-day period probably reflected the times required for transiently expressing cells to synthesize, process and accumulate sufficient amounts of epitopically labeled ribosomal protein to permit its detection by indirect immunofluorescence microscopy.

All of the mutant RPS14 alleles described in this report encode proteins that were efficiently transported to $\mathrm{CHO}$ cell nucleoli, indicating that none of the point mutations examined seriously compromised S14's nucleolar localization. In contrast, immunofluorescence analysis of the proteins expressed from a series of epitopically-tagged RPS14 deletion, insertion and substitution transgenes indicate that a basic ten amino acid sequence near the protein's carboxyl terminus, RRKGGRRGRR, is essential for S14's nuclear localization (unpublished observations).

The final steps of eukaryotic ribosome biogenesis occur within the cells' nucleolus. Several nucleolar proteins have been implicated in the assembly and maturation of ribosomal subunit particles (Hugle et al., 1985; Steitz et al., 1988; Borer et al., 1989; Meier and Blobel, 1992, 1994) as well as in the export of mature ribosomal subunits to the cell's cytoplasm (Khanna-Gupta and Ware, 1989; Bataillé et al., 1990; Ware and Khanna-Gupta, 1990). In addition, previous studies from this laboratory indicate that r-protein S14 contributes significantly to the structural integrity of mammalian $40 \mathrm{~S}$ ribosomal subunits. When $40 \mathrm{~S}$ ribosomes purified from an emetine-resistant mutant $\mathrm{CHO}$ cell line were treated with 0.5 $\mathrm{M} \mathrm{KCl}$, a condition which is used routinely to purify wildtype mammalian ribosomal subunits, they dissociated into a pair of sub-ribosomal particles which lacked S14 as well as several other structural r-proteins (Madjar et al., 1983). In light of these observations, the null mutations which appear to preclude S14's incorporation into pre-ribosomal subunit particles (listed under Group C in Table 1) are likely to affect amino acid residues that mediate the associations between $\mathrm{S} 14$ and other $40 \mathrm{~S}$ ribosomal structural proteins or participate in interactions between S14 and nucleolar proteins involved in ribosomal subunit assembly, maturation and transport.

It is interesting that sixteen of the seventeen amino acid residues altered by randomly-induced null mutations in the human RPS14 locus (all but Cys-31) are stringently conserved among the RPS14 loci carried by diverse eukaryotic species (Table 2). These include amino acids located within RPS14 domains B, C and D (Fig. 5). This striking pattern of evolutionary conservation is consistent with our conclusion that amino acid residues affected by null mutations in the human RPS14 locus are essential for intracellular transport and nucleolar processing of r-protein S14 as well as for the protein's biological activity in mature cytoplasmic $40 \mathrm{~S}$ ribosomal subunits.
The authors thank Dr Richard A. Consigli for his help with indirect immunofluorescence microscopy and Dr David A. Rintoul for his suggestions concerning this manuscript. They also acknowledge the expert technical assistance provided by Mrs Andrea Fernandez, $\mathrm{Mr}$ Ralph S. Najarian and Mrs Marla M. Pyle. This research was supported by grants GM23013 and GM38932 from the National Institute of General Medical Sciences and a postdoctoral research fellowship to J.M.N. from the Kansas Health Foundation (Wichita, KS). This report is contribution no. 97-67-J from the Kansas Agricultural Experiment Station.

\section{REFERENCES}

Aerne, B. L., Baader, C. D., Schmid, V. and Schuchert, P. (1994). The sequence of a cDNA encoding ribosomal protein S14 from the hydrozoan Podocoryne carnea reveals high evolutionary conservation. Gene 140, 243 246

Bataillé, N., Helser, T. and Fried, H. M. (1990). Cytoplasmic transport of ribosomal subunits microinjected into the Xenopus laevis oocyte nucleus: A generalized, facilitated process. J. Cell Biol. 111, 1571-1582.

Boersma, D., McGill, S. M., Mollenkamp, J. W. and Roufa, D. J. (1979a). Emetine resistance in Chinese hamster cells. Analysis of ribosomal proteins prepared from mutant cells. J. Biol. Chem. 254, 559-567.

Boersma, D., McGill, S. M., Mollenkamp, J. W. and Roufa, D. J. (1979b). Emetine resistance in Chinese hamster cells is linked genetically with an altered $40 \mathrm{~S}$ ribosomal subunit protein S20*. Proc. Nat. Acad. Sci. USA 76, 415-419.

Borer, R. A., Lehner, C. F., Eppenberger, H. M. and Nigg, E. A. (1989). Major nucleolar proteins shuttle between nucleus and cytoplasm. Cell 56, 379-390.

Brown, S. J., Rhoads, D. D., Stewart, M. J., Van Slyke, B., Chen, I.-T., Johnson, T. K., Denell, R. E. and Roufa, D. J. (1988). Ribosomal protein $\mathrm{S} 14$ is encoded by a pair of highly conserved, adjacent genes on the X chromosome of Drosophila melanogaster. Mol. Cell. Biol. 8, 4314-4321.

Chen, I.-T., Dixit, A., Rhoads, D. D. and Roufa, D. J. (1986). Homologous ribosomal proteins in bacteria, yeast and humans. Proc. Nat. Acad. Sci. USA 83, 6907-6911.

Dayhoff, M. O. (1978). Atlas of Protein Sequence and Structure. National Biomedical Research Foundation, Silver Spring, MD.

Deshmukh, M., Tsay, Y.-F., Paulovich, A. G. and Woolford, J. L. Jr (1993). Yeast ribosomal protein L1 is required for the stability of newly synthesized 5S rRNA and the assembly of $60 \mathrm{~S}$ ribosomal subunits. Mol. Cell. Biol. 13, 2835-2845.

Diaz, J.-J., Rhoads, D. D. and Roufa, D. J. (1990). Genetic analysis of a vital mammalian housekeeping locus using $\mathrm{CHO}$ cells that express a transfected mutant allele. Somat. Cell Mol. Genet. 16, 517-528.

Diaz, J.-J., Rhoads, D. D. and Roufa, D. J. (1991). PCR-mediated chemical mutagenesis of cloned duplex DNAs. BioTechniques 11, 204-211.

Diaz, J.-J. and Roufa, D. J. (1992). Fine structure map of the human ribosomal protein gene RPS14. Mol. Cell. Biol. 12, 1680-1686.

Gupta, R. S. and Siminovitch, L. (1977). The molecular basis of emetine resistance in Chinese hamster ovary cells: Alteration in the $40 \mathrm{~S}$ ribosomal subunit. Cell 10, 61-66.

Hadjiolov, A. A. (1985). The Nucleolus and Ribosome Biogenesis. pp. 1-268. Springer-Verlag, New York.

Hugle, B., Scheer, U. and Franke, W. W. (1985). Ribocharin: a nuclear $M_{r}$ 40,000 protein specific to precursor particles of the large ribosomal subunit. Cell 41, 615-627.

Khanna-Gupta, A. and Ware, V. C. (1989). Nucleocytoplasmic transport of ribosomes in a eukaryotic system: Is there a facilitated transport process? Proc. Nat. Acad. Sci. USA 86, 1791-1795.

Krishnamachary, N., Ma, L., Zheng, L., Safa, A. R. and Center, M. S. (1994). Analysis of MRP gene expression and function in HL60 cells isolated for resistance to adriamycin. Oncol. Res. 6, 119-127.

Kumar, A. and Warner, J. R. (1972). Characterization of ribosomal precursor particles from Hela cell nucleoli. J. Mol. Biol. 63, 233-246.

Larkin, J. C., Thompson, J. R. and Woolford, J. L. Jr (1987). Structure and expression of the Saccharomyces cerevisiae CRY1 gene: A highly conserved ribosomal protein gene. Mol. Cell. Biol. 7, 1764-1775.

Larkin, J. C., Hunsperger, J. P., Culley, D., Rubenstein, I. and Silflow, C. D. (1989). The organization and expression of a maize ribosomal protein gene family. Genes Dev. 3, 500-509. 
Larson, G. P. and Rossi, J. J. (1991). Altered response to growth rate changes in Kluveromyces lactis versus Saccharomyces cerevisiae as demonstrated by heterologous expression of ribosomal protein 59 (CRY1). Nucl. Acids Res. 19, 4701-4707.

Madjar, J.-J., Nielsen-Smith, K., Frahm, M. and Roufa, D. J. (1982). Emetine resistance in Chinese hamster ovary cells is associated with an altered ribosomal protein S14 mRNA. Proc. Nat. Acad. Sci. USA 79, 10031007.

Madjar, J.-J., Frahm, M., McGill, S. M. and Roufa, D. J. (1983). Ribosoma protein S14 is altered by two-step emetine resistance mutations in Chinese hamster cells. Mol. Cell. Biol. 3, 190-197.

Meier, U. T. and Blobel, G. (1992). Nopp140 shuttles on tracks between nucleolus and cytoplasm. Cell 70, 127-138.

Meier, U. T. and Blobel, G. (1994). NAP57, a mammalian nucleolar protein with a putative homolog in yeast and bacteria. J. Cell Biol. 127, 1505-1514.

Melese, T. and Xue, Z. (1995). The nucleolus: An organelle formed by the activity of building a ribosome. Curr. Opin. Cell Biol. 7, 319-324.

Moritz, M., Paulovich, A. G., Tsay, Y.-F. and Woolford, J. L. Jr (1990) Depletion of yeast ribosomal proteins L16 or rp59 disrupts ribosome assembly. J. Cell Biol. 111, 2261-2274.

Moritz, M., Pulaski, B. A. and Woolford, J. L. Jr (1991). Assembly of $60 \mathrm{~S}$ ribosomal subunits is perturbed in temperature-sensitive yeast mutants defective in ribosomal protein L16. Mol. Cell. Biol. 11, 5681-5692.

Nakamichi, N., Rhoads, D. D. and Roufa, D. J. (1983). The Chinese hamster cell emetine resistance gene: Analysis of cDNA and genomic sequences encoding ribosomal protein S14. J. Biol. Chem. 258, 13236-13242.

Nakamichi, N., Kao, F.-T., Wasmuth, J. J. and Roufa, D. J. (1986) Ribosomal protein gene sequences map to human chromosomes 5, 8 and 17. Somat. Cell Mol. Genet. 12, 225-236.

Nelson, J. A. E., Savereide, P. B. and Lefebvre, P. A. (1994). The CRY1 gene in Chlamydomonas reinhardtii: Structure and use as a dominant selectable marker for nuclear transformation. Mol. Cell Biol. 14, 4011-4019.

Overman, P. F., Rhoads, D. D., Tasheva, E. S., Pyle, M. M. and Roufa, D. J. (1993). Multiple regulatory elements ensure accurate expression of a human ribosomal protein gene. Somat. Cell Mol. Genet. 19, 347-362.

Paz, V., Chan, Y.-L., Gluck, A. and Wool, I. G. (1989). The primary structure of rat ribosomal protein S14. Nucl. Acids Res. 17, 9484.

Perelman, D. and Boothroyd, J. C. (1990). Lack of introns in the ribosomal protein gene S14 of trypanosomes. Mol. Cell. Biol. 10, 3284-3288.

Rhoads, D. D. and Roufa, D. J. (1985). Emetine resistance in Chinese hamster cells: Structures of wild-type and mutant ribosomal protein S14 mRNAs. Mol. Cell. Biol. 5, 1655-1659.

Rhoads, D. D., Dixit, A. and Roufa, D. J. (1986). Primary structure of human ribosomal protein S14 and the gene that encodes it. Mol. Cell. Biol. 6, 27742783.
Rhoads, D. D. and Roufa, D. J. (1987a). A cloned human ribosomal protein gene functions in rodent cells. Mol. Cell. Biol. 7, 3767-3774.

Rhoads, D. D. and Roufa, D. J. (1991). Molecular evolution of the mammalian ribosomal protein gene, RPS14. Mol. Biol. Evol. 8, 503-514.

Ripmaster, T. L., Vaughn, G. P. and Woolford, J. L. Jr (1993). DRS1 to DRS7, novel genes required for ribosome assembly and function in Saccharomyces cerevisiae. Mol. Cell. Biol. 13, 7901-7912.

Roufa, D. J. (1996). PCR mediated chemical mutagenesis. In In Vitro Mutagenesis Protocols (ed. M. K. Trower), pp.357-367. Humana Press, Totowa, NJ.

Southern, P. J. and Berg, P. (1982). Transformation of mammalian cells to antibiotic resistance with a bacterial gene under control of the SV40 early region promoter. J. Mol. Appl. Genet. 1, 327-341.

Steitz, J. A., Berg, C., Hendrick, J. P., La Branche-Chabot, H., Metspalu, A., Rinke, J. and Yario, T. (1988). A 5s rRNA/L5 complex is a precursor to ribosome assembly in mammalian cells. J. Cell Biol. 106, 545-556.

Studier, F. W., Rosenberg, A. H., Dunn, J. J. and Dubendorff, J. W. (1990). Use of T7 RNA polymerase to direct expression of cloned genes. Meth Enzymol. 185, 60-89.

Tasheva, E. S. and Roufa, D. J. (1993). Deoxycytidine methylation and the origin of spontaneous transition mutations in mammalian cells. Somat. Cell Mol. Genet. 19, 275-283.

Tyler, B. M. and Harrison, K. (1990). A Neurospora crassa ribosomal protein gene homologous to yeast $C R Y 1$ contains sequences potentially coordinating its transcription with rRNA genes. Nucl. Acids Res. 18, 5759-5765.

Ware, V. C. and Khanna-Gupta, A. (1990). Nucleocytoplasmic transport of ribosomal subunits. In The Ribosome. Structure, Function and Evolution (ed. W. E. Hill, A. Dahlberg, R. A. Garrett, P. B. Moore, D. Schlessinger and J. R. Warner), pp. 470-476. ASM, Washington, DC.

Warner, J. R. (1989). Synthesis of ribosomes in Saccharomyces cerevisiae. Microbiol. Rev. 53, 256-271.

Warner, J. R. and Soeiro, R. (1967). Nascent ribosomes from HeLa cells. Proc. Nat. Acad. Sci. USA 58, 1984-1990.

Wilson, R., Ainscough, R., Anderson, K., Baynes, C., Berks, M., Bonfield, J., Burton, J., Connell, M., Copsey, T., Cooper, J. et al. (1994). 2.2 MB of contiguous nucleotide sequence from chromosome III of C. elegans. Nature 368, 32-38.

Yeh, L.-C. C. and Lee, J. C. (1995). Contributions of multiple basic amino acids in the C-terminal region of yeast ribosomal protein L1 to 5S rRNA binding and 60 S ribosome stability. J. Mol. Biol. 246, 295-307.

(Received 17 December 1996 - Accepted 23 January 1997) 